Article

\title{
Montmorillonite Clay-Promoted, Solvent-Free Cross-Aldol Condensations under Focused Microwave Irradiation
}

\author{
Damiano Rocchi, Juan F. González and J. Carlos Menéndez * \\ Departamento de Química Orgánica y Farmacéutica, Facultad de Farmacia, Universidad Complutense, \\ Madrid 28040, Spain; E-Mails: rocchid83@gmail.com (D.R.); juanfrangn@ucm.es (J.F.G.) \\ * Author to whom correspondence should be addressed; E-Mail: josecm@ucm.es; \\ Tel.: +34-91-394-1840; Fax: +34-91-394-1822.
}

Received: 27 March 2014; in revised form: 14 May 2014 / Accepted: 26 May 2014 /

Published: 4 June 2014

\begin{abstract}
An environmentally benign, clean and general protocol was developed for the synthesis of aryl and heteroaryl trans-chalcones. This method involved solvent-free reaction conditions under microwave irradiation in the presence of a clay-based catalyst, and afforded the target compounds in good yields and short reaction times. Furthermore, the same conditions allowed the synthesis of symmetrical, diarylmethylene- $\alpha, \beta$-unsaturated ketones from aromatic aldehydes and ketones.
\end{abstract}

Keywords: heterogenous catalysis; clays as catalysts; Lewis acids; condensation reactions; green chemistry; aldehydes; enones

\section{Introduction}

Chalcones (trans-1,3-diaryl-2-propen-1-ones) are a very important class of compounds due to their occurrence in Nature and their interesting and versatile pharmacological properties, as summarized in several reviews [1-5]. These properties include antineoplastic [5-7], antimalarial [8], antiviral (HIV) $[9,10]$, antibacterial $[4,11,12]$, antioxidant [12] and anti-inflammatory [4,13] activities, among others. These compounds are also flexible scaffolds for the construction of five- and six-membered rings or their subsequent elaboration into polycyclic systems [14,15]. Chalcones are traditionally accessed by cross-aldol condensations of aryl methyl ketones and aromatic aldehydes in the presence of alkali [16-18], a reaction that requires the use of an organic solvent and a highly polluting alkaline base and in most cases needs to be followed by purification by column chromatography, leading 
again to waste generation in the form of volatile organic solvents and discarded chromatographic stationary phases.

Economic and environmental concerns connected to the practice of organic synthesis have received especial attention in recent years. In this context, a particularly important area is the development of synthetic processes in the absence of solvents [19-22]. Microwave-assisted organic synthesis (MAOS) has emerged as an efficient and powerful tool in this area [23-28] and often leads to simple protocols, short processing times, increased product yields, energy savings [29] and lower costs, thereby enabling environmentally friendly processes [30]. On the other hand, methods based on the use of heterogeneous catalysts are widely used in industrial fine and pharmaceutical chemistry, and play an important role in the current bid for the development of green synthetic processes. In particular, there is much interest in the use of clays as solid acid catalysts because of their desirable properties such as environmental compatibility, non-corrosive and non-toxic nature, low cost and, furthermore, because they often allow very simple isolation procedures. To summarize, heterogeneous catalysis is crucial to chemical technology, and clays in particular are finding increasing applications as catalysts [31-34].

In this paper, we describe a method that combines the desirable features of both approaches and its application to the preparation of chalcones. The need for this research became apparent in the course of our program on the use of aryl and heteroaryl trans-chalcones in heterocyclic synthesis [35-38], when we noticed the shortcomings of the currently available protocols for the synthesis of the required starting materials. Thus, we present here our studies on a solvent-free protocol for their synthesis under microwave irradiation conditions in the presence of a montmorillonite clay catalyst, its application to a large number of examples in order to establish its scope and a brief study of its subsequent generalization to other types of substrates.

\section{Results and Discussion}

We started our study by examining the model cross aldol condensation reaction between acetophenone (1a) and benzaldehyde (2a) at a relatively large scale $(8.6 \mathrm{mmol})$ in the presence of montmorillonite KSF (MKSF). The choice of catalyst was based on literature precedent for the thermal cross-condensation of acetophenone and benzaldehyde in the presence of clay although we were concerned about its generality, since the scope of this literature method was quite narrow [39]. Thus, we set out to optimize conditions for this model reaction by varying the following experimental parameters: temperature, time, stoichiometry, and amount of clay. In order to study the influence of temperature, an equimolecular mixture of $\mathbf{1 a}$ and $\mathbf{2 a}$ with $0.3 \mathrm{~g} / \mathrm{mol}$ of the clay catalyst was irradiated under focused microwave for 1 hour. When the reaction mixture was heated at $100{ }^{\circ} \mathrm{C}$ or $120{ }^{\circ} \mathrm{C}$, poor conversions were observed (Table 1, entries 1 and 2), but a further increase in the reaction temperature to $150{ }^{\circ} \mathrm{C}$ afforded chalcone $3 \mathbf{a}$ in a very good $88 \%$ yield (Table 1 , entry 3 ). The next parameter that we investigated was the amount of catalyst, and to this end we performed the reaction with an equimolecular mixture of $\mathbf{1 a}$ and $\mathbf{2 a}$, for 1 hour at $150{ }^{\circ} \mathrm{C}$, in the presence of MKSF $0.06,0.12,0.24$ and 0.30 gram of clay per mol of 1a. These experiments led us to select $0.24 \mathrm{~g} / \mathrm{mol}$ as the optimal clay/substrate ratio (Table 1, entries 5 to 8). Under these conditions, reaction times below $1 \mathrm{~h}$ (entries 9 and 10) proved to be detrimental to conversion and were therefore avoided in further experiments. We also observed that an increase of the 1a/2a ratio led to decreased yield (Table 1, entry 11). When 
the reaction was carried out in a multigram scale, an increase in the temperature was required in order to obtain chalcone 3a in a good yield (Table 1, entry 12). Finally, in order to compare the performance of microwave irradiation versus conventional heating, the reaction was performed at $150{ }^{\circ} \mathrm{C}$ in an oil bath using the optimal 1a/2a ratio and amount of clay. In this experiment, a very long reaction time $(20 \mathrm{~h})$ was needed for the reaction to achieve completion, and $\mathbf{3 a}$ was isolated in a poor $16 \%$ yield, together with many unidentified by-products (Table 1, entry 13). To summarize these experiments, it can be concluded that focused microwave irradiation has a highly beneficial effect on the reaction, both in terms of yields and reaction times.

Table 1. Optimization of the synthesis of model chalcone 3a.

\begin{tabular}{|c|c|c|c|c|c|}
\hline Entry & $1 \mathbf{a} / \mathbf{2 a}$ & $\mathbf{T}\left({ }^{\circ} \mathbf{C}\right)$ & Time & $\begin{array}{c}\text { KSF/substrate } \\
\text { ratio }(\mathrm{g} / \mathrm{mol})\end{array}$ & Yield $(\%)^{a}$ \\
\hline 1 & $1 / 1$ & $100^{\circ} \mathrm{C}$ & $60 \mathrm{~min}$ & 0.30 & 8 \\
\hline 2 & $1 / 1$ & $120^{\circ} \mathrm{C}$ & $60 \mathrm{~min}$ & 0.30 & 23 \\
\hline 3 & $1 / 1$ & $150^{\circ} \mathrm{C}$ & $60 \mathrm{~min}$ & 0.30 & 88 \\
\hline 4 & $1 / 1$ & $160^{\circ} \mathrm{C}$ & $60 \mathrm{~min}$ & 0.30 & 88 \\
\hline 5 & $1 / 1$ & $150^{\circ} \mathrm{C}$ & $60 \mathrm{~min}$ & 0.06 & 5 \\
\hline 6 & $1 / 1$ & $150^{\circ} \mathrm{C}$ & $60 \mathrm{~min}$ & 0.12 & 81 \\
\hline 7 & $1 / 1$ & $150^{\circ} \mathrm{C}$ & $60 \mathrm{~min}$ & 0.24 & 97 \\
\hline 8 & $1 / 1$ & $150^{\circ} \mathrm{C}$ & $60 \mathrm{~min}$ & 0.30 & 88 \\
\hline 9 & $1 / 1$ & $150^{\circ} \mathrm{C}$ & $40 \mathrm{~min}$ & 0.24 & 74 \\
\hline 10 & $1 / 1$ & $150^{\circ} \mathrm{C}$ & $20 \mathrm{~min}$ & 0.24 & 50 \\
\hline 11 & $2 / 1$ & $150^{\circ} \mathrm{C}$ & $60 \mathrm{~min}$ & 0.24 & 86 \\
\hline 12 & $1 / 1$ & $160^{\circ} \mathrm{C}$ & $60 \mathrm{~min}$ & 0.24 & $78^{b}$ \\
\hline 13 & $1 / 1$ & $150^{\circ} \mathrm{C}$ & $20 \mathrm{~h}$ & 0.29 & $16^{\mathrm{c}}$ \\
\hline
\end{tabular}

a Isolated yields, when the reaction was performed under microwave irradiation at $0.86 \mathrm{mmol}$ scale, except where noted otherwise; ${ }^{b}$ Isolated yields, when the reaction was performed under microwave irradiation in a $30 \mathrm{mmol} \mathrm{scale;}{ }^{\mathrm{c}}$ Isolated yield under reflux conditions.

The substrate scope of the cross aldol condensation reaction in the presence of the MKSF clay catalyst was explored with a variety of substituted acetophenone substrates containing either electron donating or electron withdrawing groups, with the results shown in Scheme 1 and Table 2. As expected, the presence of electron-releasing substituents in the acetophenone component, which acts as the nucleophile, is slightly beneficial to yield (compare, for instance, the yields in entries 1, 10, 19, 23 and 26). The reaction was not sensitive to steric hindrance in the aldehyde, since it tolerates well the presence of ortho substituents (compare the yields in entries 4-5, 7-9 and 15-16). Generally speaking, the substituents at the aromatic ring of the aldehyde component did not have a significant influence in the yield, but it is remarkable that some of the best results corresponded to reactions with methoxybenzaldehyde derivatives (entries 2, 11, 15, 20), in spite of the fact that the electron-releasing nature of the methoxy substituent should lead to a lower reactivity as electrophiles. 
Scheme 1. Clay-promoted synthesis of chalcones under microwave irradiation.

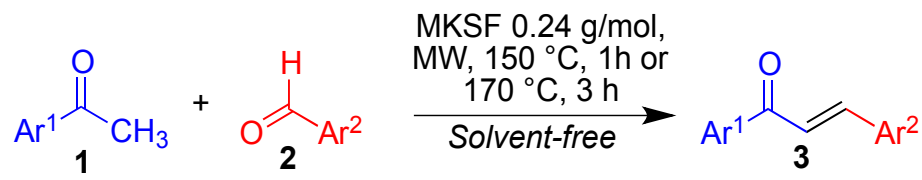

Table 2. Scope and yields in the synthesis of chalcones 3.

\begin{tabular}{|c|c|c|c|c|}
\hline Entry & $A \mathbf{r}^{1}$ & $A r^{2}$ & Compound & Yield $(\%)^{a}$ \\
\hline 1 & $\mathrm{C}_{6} \mathrm{H}_{5}$ & $\mathrm{C}_{6} \mathrm{H}_{5}$ & $3 a$ & 97 \\
\hline 2 & $\mathrm{C}_{6} \mathrm{H}_{5}$ & 4- $\mathrm{MeOC}_{6} \mathrm{H}_{4}$ & $3 b$ & 85 \\
\hline 3 & $\mathrm{C}_{6} \mathrm{H}_{5}$ & $4-\mathrm{MeC}_{6} \mathrm{H}_{4}$ & $3 c$ & 55 \\
\hline 4 & $\mathrm{C}_{6} \mathrm{H}_{5}$ & $4-\mathrm{ClC}_{6} \mathrm{H}_{4}$ & $3 d$ & 74 \\
\hline 5 & $\mathrm{C}_{6} \mathrm{H}_{5}$ & $2-\mathrm{ClC}_{6} \mathrm{H}_{4}$ & $3 e$ & 77 \\
\hline 6 & $\mathrm{C}_{6} \mathrm{H}_{5}$ & $4-\mathrm{BrC}_{6} \mathrm{H}_{4}$ & $3 f$ & 69 \\
\hline 7 & $\mathrm{C}_{6} \mathrm{H}_{5}$ & $2-\mathrm{NO}_{2} \mathrm{C}_{6} \mathrm{H}_{4}$ & $3 g$ & 51 \\
\hline 8 & $\mathrm{C}_{6} \mathrm{H}_{5}$ & $3-\mathrm{NO}_{2} \mathrm{C}_{6} \mathrm{H}_{4}$ & $3 \mathrm{~h}$ & 44 \\
\hline 9 & $\mathrm{C}_{6} \mathrm{H}_{5}$ & $4-\mathrm{NO}_{2} \mathrm{C}_{6} \mathrm{H}_{4}$ & $3 \mathrm{i}$ & $43(57)^{b}$ \\
\hline 10 & 4- $\mathrm{MeOC}_{6} \mathrm{H}_{4}$ & $\mathrm{C}_{6} \mathrm{H}_{5}$ & $3 \mathrm{j}$ & 91 \\
\hline 11 & 4- $\mathrm{MeOC}_{6} \mathrm{H}_{4}$ & $4-\mathrm{MeOC}_{6} \mathrm{H}_{4}$ & $3 \mathrm{k}$ & 83 \\
\hline 12 & 4- $\mathrm{MeOC}_{6} \mathrm{H}_{4}$ & $4-\mathrm{BrC}_{6} \mathrm{H}_{4}$ & 31 & 73 \\
\hline 13 & $4-\mathrm{MeC}_{6} \mathrm{H}_{4}$ & $\mathrm{C}_{6} \mathrm{H}_{5}$ & $3 \mathrm{~m}$ & 95 \\
\hline 14 & 4- $\mathrm{MeOC}_{6} \mathrm{H}_{4}$ & $4-\mathrm{NO}_{2} \mathrm{C}_{6} \mathrm{H}_{4}$ & $3 n$ & 55 \\
\hline 15 & 4- $\mathrm{MeC}_{6} \mathrm{H}_{4}$ & $2-\mathrm{MeOC}_{6} \mathrm{H}_{4}$ & 30 & 93 \\
\hline 16 & 4- $\mathrm{MeC}_{6} \mathrm{H}_{4}$ & 4- $\mathrm{MeC}_{6} \mathrm{H}_{4}$ & $3 p$ & 77 \\
\hline 17 & 4- $\mathrm{MeC}_{6} \mathrm{H}_{4}$ & $4-\mathrm{BrC}_{6} \mathrm{H}_{4}$ & $3 q$ & 76 \\
\hline 18 & 4- $\mathrm{MeC}_{6} \mathrm{H}_{4}$ & $2-\mathrm{NO}_{2} \mathrm{C}_{6} \mathrm{H}_{4}$ & $3 r$ & 66 \\
\hline 19 & $4-\mathrm{ClC}_{6} \mathrm{H}_{4}$ & $\mathrm{C}_{6} \mathrm{H}_{5}$ & $3 \mathrm{~s}$ & 54 \\
\hline 20 & $4-\mathrm{ClC}_{6} \mathrm{H}_{4}$ & $3-\mathrm{OMeC}_{6} \mathrm{H}_{4}$ & $3 \mathrm{t}$ & 78 \\
\hline 21 & $4-\mathrm{ClC}_{6} \mathrm{H}_{4}$ & $4-\mathrm{BrC}_{6} \mathrm{H}_{4}$ & $3 u$ & 64 \\
\hline 22 & $4-\mathrm{ClC}_{6} \mathrm{H}_{4}$ & $2-\mathrm{NO}_{2} \mathrm{C}_{6} \mathrm{H}_{4}$ & $3 \mathrm{v}$ & 48 \\
\hline 23 & $4-\mathrm{BrC}_{6} \mathrm{H}_{4}$ & $\mathrm{C}_{6} \mathrm{H}_{5}$ & $3 w$ & 60 \\
\hline 24 & $4-\mathrm{BrC}_{6} \mathrm{H}_{4}$ & $4-\mathrm{BrC}_{6} \mathrm{H}_{4}$ & $3 x$ & 86 \\
\hline 25 & $4-\mathrm{BrC}_{6} \mathrm{H}_{4}$ & $4-\mathrm{NO}_{2} \mathrm{C}_{6} \mathrm{H}_{4}$ & $3 y$ & 49 \\
\hline 26 & $4-\mathrm{NO}_{2} \mathrm{C}_{6} \mathrm{H}_{4}$ & $\mathrm{C}_{6} \mathrm{H}_{5}$ & $3 z$ & $65^{c}$ \\
\hline 27 & $4-\mathrm{NO}_{2} \mathrm{C}_{6} \mathrm{H}_{4}$ & $4-\mathrm{OMeC}_{6} \mathrm{H}_{4}$ & $3 a a$ & $64^{c}$ \\
\hline 28 & $4-\mathrm{NO}_{2} \mathrm{C}_{6} \mathrm{H}_{4}$ & 4- $\mathrm{MeC}_{6} \mathrm{H}_{4}$ & $3 a b$ & $77^{c}$ \\
\hline 29 & $4-\mathrm{NO}_{2} \mathrm{C}_{6} \mathrm{H}_{4}$ & $4-\mathrm{BrC}_{6} \mathrm{H}_{4}$ & $3 a c$ & $68^{c}$ \\
\hline 30 & $4-\mathrm{NO}_{2} \mathrm{C}_{6} \mathrm{H}_{4}$ & $4-\mathrm{NO}_{2} \mathrm{C}_{6} \mathrm{H}_{4}$ & $3 \mathrm{ad}$ & $60^{c}$ \\
\hline 31 & $\mathrm{C}_{6} \mathrm{H}_{5}$ & & $3 a e$ & 57 \\
\hline 32 & $\mathrm{C}_{6} \mathrm{H}_{5}$ & & $3 \mathrm{af}$ & 63 \\
\hline 33 & $4-\mathrm{MeC}_{6} \mathrm{H}_{4}$ & & $3 \mathrm{ag}$ & 54 \\
\hline 34 & $4-\mathrm{MeC}_{6} \mathrm{H}_{4}$ & $\mathrm{MeO}^{-}$ & $3 a h$ & 64 \\
\hline
\end{tabular}


Table 2. Cont.

\begin{tabular}{|c|c|c|c|c|}
\hline Entry & $A \mathbf{r}^{1}$ & $A r^{2}$ & Compound & Yield $(\%)^{2}$ \\
\hline 35 & $4-\mathrm{BrC}_{6} \mathrm{H}_{4}$ & & 3ai & 48 \\
\hline 36 & $\mathrm{C}_{6} \mathrm{H}_{5}$ & & 3aj & 85 \\
\hline 37 & & $\mathrm{C}_{6} \mathrm{H}_{5}$ & $3 \mathrm{ak}$ & 60 \\
\hline 38 & & & $3 \mathrm{al}$ & 97 \\
\hline 39 & & $2-\mathrm{NO}_{2} \mathrm{C}_{6} \mathrm{H}_{4}$ & $3 \mathrm{am}$ & 45 \\
\hline 40 & & $\mathrm{C}_{6} \mathrm{H}_{5}$ & $3 a n$ & 54 \\
\hline 41 & $\mathrm{C}_{6} \mathrm{H}_{5}$ & & $3 a o$ & 78 \\
\hline 42 & & & $3 a p$ & 92 \\
\hline
\end{tabular}

${ }^{\text {a }}$ General reaction conditions: A mixture of aldehyde $2(0.86 \mathrm{mmol})$, ketone $\mathbf{1}(0.86 \mathrm{mmol})$ and MKSF (200 mg) in a sealed tube, was heated under microwave irradiation at $150{ }^{\circ} \mathrm{C}$ for $1 \mathrm{~h}$; ${ }^{b}$ Reaction conditions for the reaction proceeding in $57 \%$ yield: $170{ }^{\circ} \mathrm{C}, 3 \mathrm{~h}$; ${ }^{\mathrm{c}}$ Reaction conditions for entries $26-30$ : A mixture of aldehyde $2(0.86 \mathrm{mmol})$, ketone $1(0.86 \mathrm{mmol})$ and MKSF $(200 \mathrm{mg})$ in a sealed tube, was heated under microwave irradiation at $170{ }^{\circ} \mathrm{C}$ for $3 \mathrm{~h}$.

Since the catalytic affect of the clay can be attributed to the Lewis acid activity of its metallic centers (Scheme 2a), the good reactivity of the methoxy derivatives can be explained by accepting that coordination of the oxygen atom in the OMe group with cationic centers in the clay attenuates its electron-releasing effect (Scheme 2b) [40]. Another special case was that of nitrobenzaldehyde derivatives which, again unexpectedly, gave relatively low yields (entries 7, 8, 9, 13, 18, 22, 25, 30-35). In this case, we propose that the lower reactivity is due to an increased activation energy associated to stabilizing interactions of the aldehyde with the clay by coordinating two of the cationic centers (Scheme 2c). In agreement to this explanation, we found an increase in yield from $43 \%$ to $57 \%$ for the case of compound $3 \mathbf{i}$ when changing the conditions from $150{ }^{\circ} \mathrm{C}, 1 \mathrm{~h}$ to $170{ }^{\circ} \mathrm{C}, 3 \mathrm{~h}$ (enthy 9). Unfortunately, higher temperatures could not be used because they led to the decomposition of $p$-nitrobenzaldehyde. Finally, in order to demonstrate the wide application of this methodology, the reaction was carried out with selected examples of heteroaromatic aldehydes and ketones, to give good yields of compounds 3aj to 3ap (entries 36-42).

Scheme 2. Explanation proposed for the observed substituent effects on yield.

a)

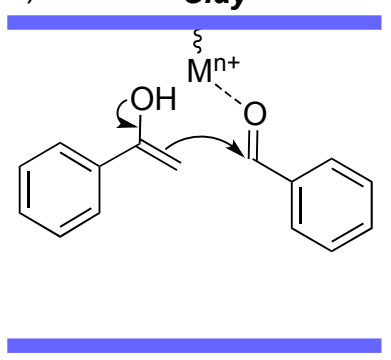

b)

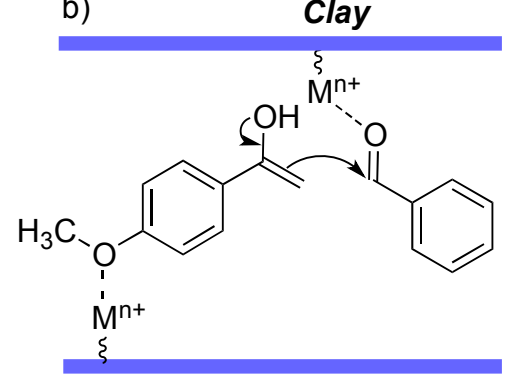

c)

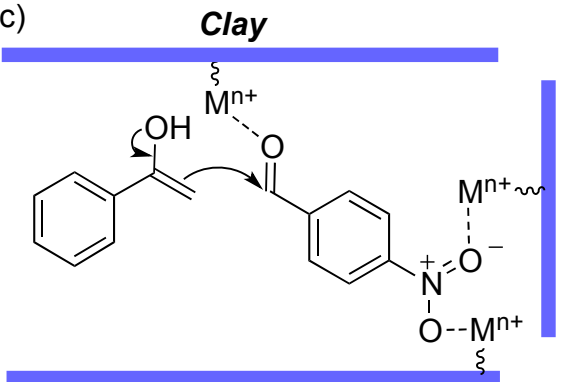


In order to further demonstrate the generality of this methodology, the pseudo three-component, double aldol reactions of representative aliphatic ketones with two equivalents of benzaldehyde were briefly examined under the optimal microwave conditions previously developed, leading to compounds 5-7 in good to excellent yields. Also, one example of a Knoevenagel reaction was carried out, affording compound 8 [41] in an excellent 92\% yield (Scheme 3).

Scheme 3. Additional examples showing the generality of the clay-promoted condensations.

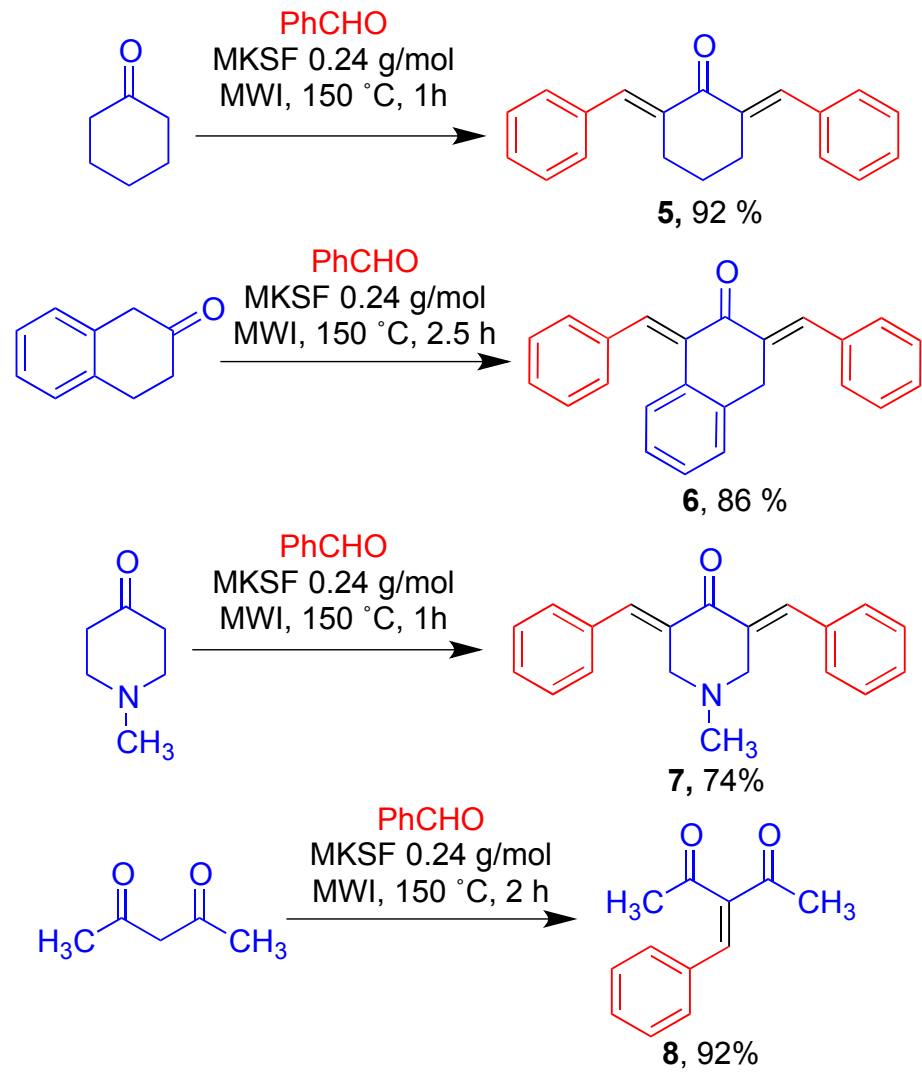

\section{Experimental Section}

\subsection{General Information}

Melting points were measured in open capillary tubes and are uncorrected. A CEM Discover focused microwave synthesizer with a maximum microwave power level of $400 \mathrm{~W}$ and microwave frequency of 2,444 MHz was employed. The ${ }^{1} \mathrm{H}-\mathrm{NMR}$ and ${ }^{13} \mathrm{C}-\mathrm{NMR}$ spectra were recorded on a Bruker (Avance) $250 \mathrm{MHz}$ NMR instrument maintained by the CAI de Resonancia Magnética, Universidad Complutense, using unless indicated otherwise $\mathrm{CDCl}_{3}$ as solvent and the residual $\mathrm{CHCl}_{3}$ as reference. Chemical shifts are given in parts per million ( $\delta$ scale) and the coupling constants are given in Hertz. Silica gel-G plates (Merck) were used for TLC analysis. Elemental analyses were measured by the CAI de Microanálisis Elemental, Universidad Complutense, on a Leco 932 CHNS analyser. IR spectra were recorded on a Perkin Elmer Paragon 1000 FT IR instrument (neat samples on a $\mathrm{NaCl}$ window). Montmorillonite KSF (product number 28,153-0) was purchased from Sigma-Aldrich (Madrid, Spain) and used as received. This particular clay has 20-25 $\mu \mathrm{m}$ particle size and a surface area of $20-40 \mathrm{~m}^{2} / \mathrm{g}$. 


\subsection{General Procedure for Cross Aldol Condensations}

A mixture of the suitable aldehyde $(1.0 \mathrm{mmol})$, acetophenone $(1.0 \mathrm{mmol})$ and clay catalyst (240 mg) was warmed at $150{ }^{\circ} \mathrm{C}$ in a sealed tube under microwave irradiation, for $1 \mathrm{~h}$. In the reactions involving solid starting materials, they were thoroughly mixed by grinding in a mortar before irradiation. The reaction mixture was diluted with hot ethanol $(20 \mathrm{~mL})$, the catalyst was filtered off, the solvent was evaporated and the residue was purified by crystallization $(\mathrm{EtOH})$ for solid chalcones (compounds 3a-3d, 3f-3m, 3p-3ar) or by column chromatography (silica gel, ethyl acetate/hexanes) for oily chalcones (compounds 3e, 3o), to afford the pure final products. All yields were calculated from isolated products. Characterization data for previously unknown compounds are given below. For full characterization data, see the Supporting Information.

(E)-3-(5-Bromo-2-nitrophenyl)-1-(p-tolyl)-2-propen-1-one (3ag). White solid (54\%). M.p. 164-166 ${ }^{\circ} \mathrm{C}$. IR $v_{\max }(\mathrm{KBr}): 1663,1598,1520 \mathrm{~cm}^{-1} .{ }^{1} \mathrm{H}-\mathrm{NMR} \delta: 8.08(1 \mathrm{H}, \mathrm{d}, J=15.7 \mathrm{~Hz}), 8.00-7.83(4 \mathrm{H}, \mathrm{m}), 7.68$ $(1 \mathrm{H}, \mathrm{dd}, J=9.0,2.8 \mathrm{~Hz}), 7.32(3 \mathrm{H}, \mathrm{m}), 2.45(3 \mathrm{H}, \mathrm{s}) .{ }^{13} \mathrm{C}-\mathrm{NMR} \delta: 189.6,147.2,144.5,138.5,134.8$, 133.6, 133.3, 132.3, 129.7, 129.1, 128.6, 128.3, 126.7, 21.9. Anal. Calcd. for $\mathrm{C}_{16} \mathrm{H}_{12} \mathrm{BrNO}_{3}$ : C, 55.51; H, 3.49; N, 4.05. Found: C, 55.28; H, 3.21 N, 3.95.

(E)-3-(4,5-Dimethoxy-2-nitrophenyl)-1-(p-tolyl)-2-propen-1-one (3ah). White solid (64\%). M.p. 180-182 ${ }^{\circ} \mathrm{C} .{ }^{1} \mathrm{H}-\mathrm{NMR} \delta 8.20(\mathrm{~d}, J=15.7 \mathrm{~Hz}, 1 \mathrm{H}), 7.97-7.91(\mathrm{~m}, 2 \mathrm{H}), 7.67(\mathrm{~s}, 1 \mathrm{H}), 7.36-7.29$ (m, 2H), $7.20(\mathrm{~d}, J=15.7 \mathrm{~Hz}, 1 \mathrm{H}), 7.07(\mathrm{~s}, 1 \mathrm{H}), 4.06(\mathrm{~s}, 3 \mathrm{H}), 4.01(\mathrm{~s}, 3 \mathrm{H}), 2.45(\mathrm{~s}, 3 \mathrm{H}) .{ }^{13} \mathrm{C}-\mathrm{NMR} \delta 190.8$, 153.3, 150.0, 144.0, 141.4, 141.1, 135.0, 129.5, 129.1, 126.7, 126.2, 110.2, 108.1, 56.7, 56.6, 21.8. Anal. Calcd. for $\mathrm{C}_{18} \mathrm{H}_{17} \mathrm{NO}_{5}$ : C, 66.05; H, 5.23; N, 4.28. Found: C, 59.93; H, 5.09; N, 4.15.

(E)-3-(5-Bromo-2-nitrophenyl)-1-(4-bromophenyl)-2-propen-1-one (3ai). White solid (48\%). M.p. 191-193 ${ }^{\circ} \mathrm{C} .{ }^{1} \mathrm{H}-\mathrm{NMR}$, DMSO-d 6 ) $\delta: 8.49(1 \mathrm{H}, \mathrm{d}, J=2.7 \mathrm{~Hz}), 8.16(2 \mathrm{H}, \mathrm{d}, J=9.0 \mathrm{~Hz}), 8.05(1 \mathrm{H}, \mathrm{d}, J$ $=9.0 \mathrm{~Hz}), 7.98(2 \mathrm{H}, \mathrm{d}, J=3.8 \mathrm{~Hz}), 7.92(1 \mathrm{H}, \mathrm{dd}, J=9.0,2.7 \mathrm{~Hz}), 7.82(2 \mathrm{H}, \mathrm{d}, J=9.0 \mathrm{~Hz}) .{ }^{13} \mathrm{C}-\mathrm{NMR}(63$ MHz, DMSO-d 6 ) $\delta:{ }^{13} \mathrm{C}-\mathrm{NMR}(63 \mathrm{MHz}, \mathrm{DMSO}) \delta 188.0,147.8,137.7,135.9,133.7,132.0,131.8$, 130.9, 127.9, 127.6, 126.9, 126.8. Anal. Calcd. for $\mathrm{C}_{15} \mathrm{H}_{9} \mathrm{Br}_{2} \mathrm{NO}_{3}$ : C, 43.83; H, 2.21; N, 3.41. Found: C, 43.57; H, 2.39; N, 3.17 .

\section{Conclusions}

In conclusion, we have developed a solvent-free, inexpensive and fast microwave-assisted method for cross aldol condensations, catalysed by the acidic clay montmorillonite KSF, with a broad scope of application. In comparison to previously reported methods, where strong acids or bases are normally required, the protocol reported here constitutes a user- and environment-friendly alternative that proceeds normally in good to excellent yields.

\section{Supplementary Materials}

Supplementary materials can be accessed at: http://www.mdpi.com/1420-3049/19/6/7317/s1. 


\section{Acknowledgments}

Financial support from Ministerio de Economía y Competitividad (MINECO) is gratefully acknowledged (grant CTQ-2012-33272-BQU).

\section{Author Contributions}

D.R., J.F.G. and J.C.M. conceived the research and designed the experiments. D.R. and J.F.G. carried out the experiments. J.F.G. and J.C.M. wrote the paper.

\section{Conflicts of Interest}

The authors declare no conflict of interest.

\section{References and Notes}

1. Dimmock, J.R.; Elias, D.W.; Beazely, M.A.; Kandepu, N.M. Bioactivity of chalcones. Curr. Med. Chem. 1999, 6, 1125-1149.

2. Batovska D.I.; Todorova, I.T. Trends in the utilization of the pharmacological potential of chalcones. Curr. Clin. Pharmacol. 2010, 5, 1-29.

3. Sahu, N.K.; Balbhadra, S.S.; Choudhary, J.; Kohli, D.V. Exploring pharmacological significance of chalcone scaffold: A review. Curr. Med. Chem. 2012, 19, 209-225.

4. Nowakowska, Z. A review of anti-infective and anti-inflammatory chalcones. Eur. J. Med. Chem. 2007, 42, 125-137.

5. Cabrera, M.; Simoens, M.; Falchi, G.; Lavaggi, M.L.; Piro, O.E.; Castellano, E.E.; Vidal, A.; Azqueta, A.; Monge, A.; López de Ceráin, A.; et al. Synthetic chalcones, flavanones, and flavones as antitumoral agents: Biological evaluation and structure-activity relationships. Bioorg. Med. Chem. 2007, 15, 3356.

6. Xia, Y.; Yang, Z.Y.; Xia, P.; Bastow, K.F.; Nakanishi, Y.; Lee, K.H. Antitumor agents. Part 202: Novel 2'-amino chalcones: Design, synthesis and biological evaluation. Bioorg. Med. Chem. Lett. 2000, 10, 699-701.

7. Nam, N.H.; Kim, Y.; You, Y.J.; Hong, D.H.; Kim, H.M.; Ahn, B.Z. Cytotoxic 2',5'-dihydroxychalcones with unexpected antiangiogenic activity. Eur. J. Med. Chem. 2003, 38, 179-187.

8. Wu, X.; Wilairat, P.; Go, M.L. Antimalarial activity of ferrocenyl chalcones. Bioorg. Med. Chem. Lett. 2002, 12, 2299-2302.

9. Wu, J.H.; Wang, X.H.; Yi, Y.H.; Lee, K.H. Anti-AIDS agents 54. A potent anti-HIV chalcone and flavonoids from genus Desmos. Bioorg. Med. Chem. Lett. 2003, 13, 1813-1815.

10. Hu, G.; Li, X.; Zhang, X.; Li, Y.; Ma, L.; Yang, L.-M.; Liu, G.; Li, W.; Huang, J.; Shen, X.; et al. Discovery of inhibitors to block interactions of HIV-1 integrase with human LEDGF/p75 via structure-based virtual screening and bioassays. J. Med. Chem. 2012, 55, 10108-10117.

11. Nagwanshi, R.; Bakhru, M.; Jain, S. Comparative antimicrobial activities of chalcones and their photoproducts. Med. Chem. Res. 2012, 21, 1587-1596. 
12. Ahmad, M.R.; Sastry, V.G.; Bano, N.; Anwer, S.; Kumaraswamy, G. Antioxidant and antibacterial activities of some novel chalcone derivatives and their synthesis by conventional and microwave irradiation methods. J. Chem. Pharm. Res. 2011, 3, 710-717.

13. Talukdar, J.I.; Kachroo, M.; Razdan, R. Anti-inflammatory activity of some newly synthesized chalcones. Int. J. Pharm. 2013, 3, 728-733.

14. Basnet, A.; Thapa, P.; Karki, R.; Na, Y.; Jahng, Y.; Jeong, B.-S.; Jeong, T.C.; Leec, C.-S.; Lee, E.-S. 2,4,6-Trisubstituted pyridines: Synthesis, topoisomerase I and II inhibitory activity, cytotoxicity, and structure-activity relationship. Bioorg. Med. Chem. 2007, 15, 4351-4359.

15. Nepal, K.; Singh, G.; Turan, A.; Agarwal, A.; Sapra, S.; Kumar, R.; Banerjee, U.C.; Verma, P.K.; Satti, N.K.; Gupta, M.K.; et al. A rational approach for the design and synthesis of 1-acetyl-3,5-diaryl-4,5-dihydro(1H)pyrazoles as a new class of potential non-purine xanthine oxidase inhibitors. Bioorg. Med. Chem. 2011, 19, 1950-1958.

16. Kurth, E.F. The preparation of the polyhydroxychalcones. J. Am. Chem. Soc. 1939, 81, 861-862.

17. Smith, H.E.; Paulson, M.C. The preparation of chalcones from hydroxy and methoxy aldehydes and ketones. J. Am. Chem. Soc. 1954, 76, 4486-4487.

18. Zurd, L.; Horowitz, R.M. Spectral studies on flavonoid compounds. III. Polyhydroxychalcones. J. Org. Chem. 1961, 26, 2561-2563.

19. Tanaka, K.; Toda, F. Solvent-free organic synthesis. Chem. Rev. 2000, 100, 1025-1074.

20. Tanaka, K. Solvent-free Organic Synthesis; Wiley-VCH: Weinheim, Germany, 2003.

21. Martins, M.A.P.; Frizzo, C.P.; Moreira, D.N.; Buriol, L.; Machado, P. Solvent-free heterocyclic synthesis. Chem. Rev. 2009, 109, 4140-4182.

22. Zhang, W.; Cue, B.W.; Mack, J.; Muthukrishnan, S. In Green Techniques for Organic Synthesis and Medicinal Chemistry; Zhang, W., Cue, B.W., Eds.; Wiley: Chichester, UK, 2012; Chapter 11.

23. Tierney, J.; Lindstrom, P. Microwave Assisted Organic Synthesis; Blackwell: Oxford, UK, 2004.

24. Kappe, C.O. Controlled Microwave Heating in Modern Organic Synthesis. Angew. Chem. Int. Ed. 2004, 43, 6250-6284.

25. Van der Eycken, E.; Kappe, C.O.; Eds. Microwave-assisted Synthesis of Heterocycles; Springer Verlag: Berlin, Germany, 2006.

26. De la Hoz, A.; Díaz-Ortiz, A.; Moreno, A.; Sánchez-Mingallón, A.; Prieto, P.; Carrillo, J.R.; Vázquez, E.; Gómez, M.V.; Herrero, M.A. Microwave-assisted reactions in heterocyclic compounds with applications in medicinal and supramolecular chemistry. Comb. Chem. High Throughput Screen. 2007, 10, 877-902.

27. Sharma, A.; Appukkuttan, P.; van der Eycken, E. Microwave-assisted synthesis of medium-sized heterocycles. Chem. Commun. 2012, 48, 1623-1637.

28. Zhu, J.; Pallavkar, S.; Chen, M.; Yerra, N.; Luo, Z.; Colorado, H.A.; Lin, H.; Haldolaarachchige, N.; Khasanov, A.; Ho, T.C.; et al. Magnetic carbon nanostructures: Microwave energy-assisted pyrolysis vs. conventional pyrolysis. Chem. Commun. 2013, 49, 258-260.

29. For a recent example involving experimental measurements of energy consumption for standard and microwave-assisted conditions, see: Prasanna, P.; Balamurugan, K.; Perumal, S.; Menéndez, J.C. A facile, three-component domino protocol for the microwave-assisted synthesis of functionalized naphtho[2,3-b]furan-4,9-diones in water. Green Chem. 2011, 13, 2123-2129. 
30. Strauss, C.R.; Varma, R.S. Microwaves in green and sustainable chemistry. Top. Curr. Chem. 2006, 266, 199-231.

31. Varma, R.S. Clay and clay-supported reagents in organic synthesis. Tetrahedron 2002, 58, 1235-1255.

32. Nagendrappa, G. Organic synthesis using clay and clay-supported catalysts. Appl. Clay Sci. 2011, 53, 106-138.

33. Kaur, N.; Kishore, D. Montmorillonite: An efficient, heterogeneous and green catalyst for organic synthesis. J. Chem. Pharm. Res. 2012, 4, 991-1015.

34. Sridharan, V.; Menéndez, J.C. Two-step stereocontrolled synthesis of densely functionalized cyclic $\beta$-aminoesters containing four stereocenters, based on a new cerium(IV) ammonium nitrate catalyzed sequential three-component reaction. Org. Lett. 2008, 10, 4303-4306.

35. Tenti, G.; Ramos, M.T.; Menéndez, J.C. One-pot access to a library of structurally diverse nicotinamide derivatives via a three-component formal aza [3+3] cycloaddition. ACS Comb. Sci. 2012, 14, 551-557.

36. Tenti, G.; Egea, J.; Villarroya, M.; León, R.; Fernández, J.C.; Padín, J.F.; Sridharan, V.; Ramos, M.T.; Menéndez, J.C. Identification of 4,6-diaryl-1,4-dihydropyridines as a new class of neuroprotective agents. Med. Chem. Commun. 2013, 4, 590-594.

37. Rocchi, D.; González, J.F.; Menéndez, J.C. Microwave-assisted, sequential four-component synthesis of polysubstituted 5,6-dihydroquinazolinones from acyclic precursors and an oxidant-free method for their aromatization under focused microwave irradiation. Green Chem. 2013, 15, 511-517.

38. Tenti, G.; Parada, E.; León, R.; Egea, J.; Martínez-Revelles, S.; Briones, A.M.; Sridharan, V.; López, M.G.; Ramos, M.T.; Menéndez, J.C. New 5-unsubstituted dihydropyridines with improved $\mathrm{Ca}_{\vee} 1.3$ selectivity as potential neuroprotective agents against ischemic injury. J. Med. Chem. 2014, 57, 4313-4323.

39. Ballini, R.; Bosica, G.; Maggi, R.; Ricciutelli, M.; Righi, P.; Sartori, G.; Sartorio, R. Clay-catalysed solventless synthesis of trans-chalcones. Green Chem. 2001, 3, 178-180.

40. Dintzner, M.R.; Little, A.J.; Pacilli, M.; Pileggi, D.J.; Osner, Z.R.; Lyons, T.W. Montmorillonite clay-catalyzed hetero-Diels-Alder reaction of 2,3-dimethyl-1,3-butadiene with benzaldehydes. Tetrahedron Lett. 2007, 48, 1577-1579.

41. For precedent of a clay-promoted Knoevenagel reaction, see: Martín, R.M.; Ortega, E.; Rojas, M.L.; Vicente, M.A.; Banares, M.A. Ultrasound-activated Knoevenagel condensation of malononitrile with carbonylic compounds catalysed by alkaline-doped saponites. J. Chem. Technol. Biotechnol. 2005, 80, 234-238.

Sample Availability: Samples of the compounds described in this paper are available from the authors.

(C) 2014 by the authors; licensee MDPI, Basel, Switzerland. This article is an open access article distributed under the terms and conditions of the Creative Commons Attribution license (http://creativecommons.org/licenses/by/3.0/). 